Unusual cause of lower gastrointestinal bleed and

\section{abdominal pain}

A young patient with a history of systemic lupus erythematosus (SLE) complicated by lupus nephritis presented to the emergency department with vomiting, diarrhoea and diffuse abdominal pain for 7 days. The diarrhoea was watery and yellow in colour with occasional mucus and blood. The patient had a similar presentation in the past, but no specific diagnosis had been made on prior admissions. Patient denied fever, chills, rashes, night sweats or joint pain. On physical examination, vitals were within normal limits. The examination was pertinent for a soft abdomen with diffuse tenderness to palpation, without peritoneal signs. CT of the abdomen and pelvis revealed thickening of small bowel and severe colitis with relative rectal sparing and moderate terminal ileitis (figure 1). Laboratory parameters were significant for anaemia with haemoglobin of $98 \mathrm{~g} / \mathrm{L}$, leucocytosis of 14500 with left shift, C reactive protein of $3 \mathrm{mg} / \mathrm{dL}$ (normal $<0.40$ $\mathrm{mg} / \mathrm{dL}$ ), creatinine of $2.75 \mathrm{mg} / \mathrm{dL}$ (normal $0.50-1.30$ $\mathrm{mg} / \mathrm{dL}$ ), a 24 hours urine protein of $5500 \mathrm{mg} / 24$ hours (normal 50-100 mg/24 hours), decreased complement levels-C3 $44 \mathrm{mg} / \mathrm{dL}$ (normal 80-180 mg/dL) and C4 $2.97 \mathrm{mg} / \mathrm{dL}$ (normal 10-45 mg/dL), and an elevated double-stranded DNA $70 \mathrm{IU} / \mathrm{mL}$ (normal $\leq 29 \mathrm{IU} /$ $\mathrm{mL}$ ). The patient had an infectious workup for colitis, including gastrointestinal (GI) PCR panel, Clostridium difficile and stool culture (including ova/parasite/acidfast bacilli), all eventually negative. Subsequently, colonoscopy was done, which revealed edematous mucosa and ulcers (figure 2). Biopsies from colonoscopy were taken, and results are shown in (figure 3).

\section{QUESTION}

What is the diagnosis?

\section{ANSWER}

Lupus vasculitis causing enteritis.

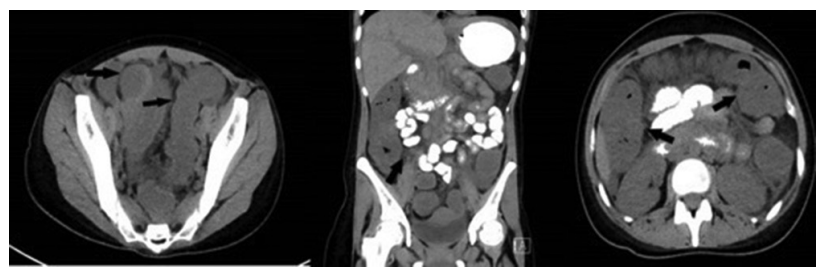

Figure 1 CT scan showing thickening of small bowel, terminal ileum and colon with relative rectal sparing (black arrows).

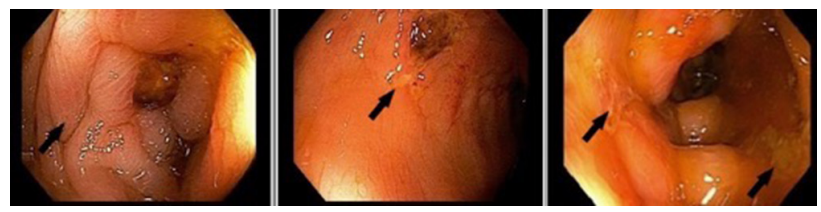

Figure 2 Colonoscopy showing edematous mucosa and scattered ulcers (black arrows) throughout left colon.

Colonoscopy revealed edematous mucosa with greater severity in the left colon. There were scattered ulcers throughout the left colon (figure 2, black arrow). Given the multisystem manifestations, small vessel vasculitis was considered as well as infection, given the patient's immunosuppression. The biopsy revealed fibrinoid necrosis along with acute inflammation (figure 3, low and high power) in the submucosa, which is highly suggestive of small vessel vasculitis. The immunohistochemistry for cytomegalovirus (CMV) and herpes simplex virus (HSV) were negative as well.

SLE is a chronic inflammatory disease of unknown cause that can affect the skin, joints, kidneys and GI system. GI involvement and related symptoms occur in up to $40 \%$ of patients. ${ }^{1}$ Common manifestations include-dysphagia, protein-losing enteropathy, intestinal pseudo-obstruction, hepatitis, pancreatitis and lupus enteritis. ${ }^{1}$ Lupus enteritis due to vasculitis is the most common cause of acute abdominal pain in SLE. The prevalence of intestinal vasculitis in patients with SLE ranges from $0.2 \%$ to $53 \% .^{2}$ A study reported lupus enteritis to be present in 22\% of SLE cases presenting as abdominal pain. ${ }^{2}$ The vasculitis associated with SLE involves inflammation of the small vessels (arteritis or venulitis). It can cause acute abdomen due to thrombosis leading to infarction, perforation and peritonitis. However, it can also present insidiously with symptoms of chronic mesenteric ischaemia. The common CT findings include bowel wall thickening, abnormal bowel wall enhancement and mesenteric oedema. There is relative rectal sparing probably due to its rich blood supply. ${ }^{23}$

Management requires treating the underlying disease with immunosuppressive agents. Our patient was treated with intravenous steroids and mycophenolate mofetil. Surgical intervention is required in case of mesenteric infarction or perforation. Special efforts should be made to rule out infection and malignancy,
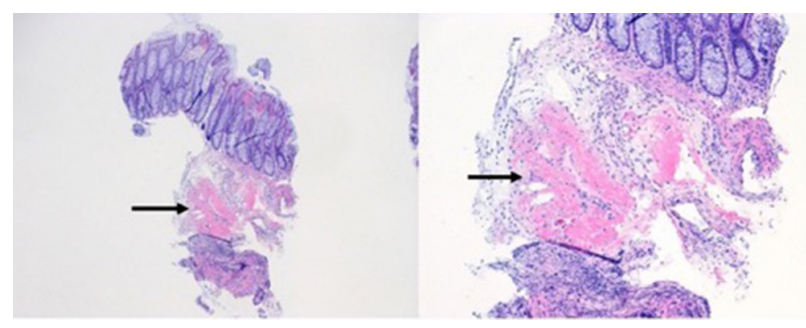

Figure 3 Biopsy showing fibrinoid necrosis along with acute inflammation in the submucosa (black arrows). 
which can occur due to immunosuppressive drugs commonly used to treat SLE.

Varun Kesar $\odot,{ }^{1}$ Komal Lakhani, ${ }^{2}$ Arun Swaminath ${ }^{2}$

${ }^{1}$ Gastroenterology, Virginia Tech Carilion School of Medicine, Roanoke, Virginia, USA

${ }^{2}$ Gastroenterology, Lenox Hill Hospital, New York, New York, USA

Correspondence to Dr Varun Kesar, Gastroenterology, Virginia Tech Carilion School of Medicine, Roanoke, VA 24016, USA; varundkl8@gmail.com

Contributors $\mathrm{VK}$ is the corresponding author and was involved in drafting the manuscript. KL is the second author who helped in the acquisition of images and correcting the manuscript.

AS is the senior author who provided supervision and made necessary corrections in the manuscript.

Funding This research has received no specific grant from any funding agency in the public, commercial or not-for-profit sectors.

Competing interests No, there are no competing interests for any author.

Patient consent for publication Not required.

Provenance and peer review Not commissioned; externally peer reviewed.

(C) Author(s) (or their employer(s)) 2020. No commercial re-use. See rights and permissions. Published by BMJ.
To cite Kesar V, Lakhani K, Swaminath A. Frontline Gastroenterology 2020;11:337-338.

Received 9 April 2019

Revised 31 May 2019

Accepted 4 June 2019

Published Online First 21 June 2019

Frontline Gastroenterology 2020;11:337-338. doi:10.1136/

flgastro-2019-101243

ORCID iD

Varun Kesar http://orcid.org/0000-0002-2422-0249

\section{REFERENCES}

1 Hoffman BI, Katz WA. The gastrointestinal manifestations of systemic lupus erythematosus: a review of the literature. Semin Arthritis Rheum 1980;9:237-47.

2 Lee C-K, Ahn MS, Lee EY, et al. Acute abdominal pain in systemic lupus erythematosus: focus on Lupus enteritis (gastrointestinal vasculitis). Ann Rheum Dis 2002;61:547-50.

3 Ko SF, Lee TY, Cheng TT, et al. CT findings at lupus mesenteric vasculitis. Acta Radiol 1997;38:115-20. 